\title{
Anomalía en el libro de Kells. Dinámicas del acontecimiento plástico
}

\section{Anomaly in the book of Kells. Dynamics of the plastic event}

TIPO DE TRABAJO: Comunicación virtual

PALABRAS CLAVE

Fotografía, edición, página, figura, texto.

KEY WORDS

Photography, edition, page, figure, text.

RESUMEN

Al igual que ocurre en un libro, una secuencia de imágenes impulsa determinados procesos de lectura propios de su estructura vermicular y de la relación causal entre los signos visuales que cohabitan o se suceden en esa secuencia. La obra fotográfica "Anomalía en el libro de Kells" (María Caro, 2018) se presenta como una serie formada por cuatro "páginas" sobredimensionadas en las que se incluyen ciertas imágenes que ponen en valor su propia dimensión y el lugar que ocupan. Como parte de la obra aparece también el pie de foto, el cual se desprende de su sentido descriptivo para convertirse en un signo visual más. Esta investigación se centra en lo que ocurre cuando la imagen fotográfica se desplaza a figura citada en un texto, pero su relación con este texto no queda limitada a una mera ilustración enciclopédica, sino que subvierte su función y se desliza por las lindes de la referencia. El texto converitdo en pie no nomina, no traduce ni enlaza de forma arbitraria a la figura que cita. ¿Cómo afecta a la lectura -ese proceso de desencriptado que se realiza de manera instantánea cuando el lector/espectador se enfrenta a la organización convencional de una página- que las conexiones entre significado y significante se materialicen no en una sino en todo un campo de posibilidades? El análisis realizado de las obras que conjugan formalmente texto e imagen se fija en el acontecimiento narrativo y su devenir en el suceso plástico.

\section{ABSTRACT}

As happens in a book, a sequence of images drives certain reading processes of its vermicular structure and the causal relationship between the visual signs that cohabit or follow each other in that sequence. The photographic work "Anomaly in the Book of Kells" (María Caro, 2018) is presented as a series of four oversized "pages" that include certain images that, in the absence of a greater definition, value their own dimension and the place they occupy. As part of the work also appears the so-called caption, which emerges from its descriptive sense to become a simple visual sign. This research focuses on what happens when the photographic image moves in a figure quoted in a text, but the relationship with this text is not limited to a mere encyclopedic illustration, but it subverts its function and slides along the boundaries of the reference. The text converted into a caption doesn't nominate, translate or link arbitrarily to the figure cited. How does it affect reading - that decryption process that takes place instantaneously when the reader / viewer faces the conventional organization of a page - that the connections between meaning and signifier materialize not just in one but in a whole field of possibilities? The analysis of works that formally combine text and image focuses into the narrative event and its becoming in the plastic event. 


\section{INTRODUCCIÓN}

Desde el año 2006 mi investigación especula con las posibilidades plásticas de los elementos propios de la edición impresa, entre ellos la fotografía -convertida en figura-, el texto, el contexto en el que ambos se insertan, la página, el pie de foto, la numeración paginal, la visión encontrada y entrecortada que provoca la doble página, la seriación, el ritmo, la secuenciación que sucede en el proceso de lectura... etc. En la producción de la serie "Anomalía en el libro de Kells" $(2018)^{1}$, la fotografía se debate entre constituirse en figura estandarizada y arbitraria en la cual el texto descansa, se explica, se ve traducido por la representación icónica; o alzarse como parte de un proyecto plástico global más allá de la convención que la define y señala. Esta línea creativa me lleva a cuestionar continuamente la fotografía y su significado, sus conexiones y su postura dentro de la totalidad del proyecto plástico, además de ahondar en las posibilidades formales y conceptuales que suscitan estas relaciones dialógicas.

La serie fotográfica "Anomalía..." forma parte de una cadena de propuestas plásticas que se suceden constantemente en la misma problemática y en sus soluciones. En este flujo de trabajo, cada nueva serie se convierte en el resultado de un ensayo de gramática visual; su análisis y contextualización dentro de las tendencias contemporáneas aportará las claves para futuras series.

Se hace necesario aclarar desde el presente apartado que el libro de fotografías o el fototexto no es en sí el objeto de estudio de esta comunicación. En absoluto se aborda la labor de elaborar fronteras o conexiones entre el catálogo fotográfico al uso y el libro como objeto plástico. Tampoco se profundiza en la narratividad de la imagen o sus posibilidades de relatar o evocar sucesos. Las obras que pudieran ser un referente formal o conceptual de la serie "Anomalía..." han sido escogidas por el hecho de que son el resultado de la unión entre texto y fotografía dentro del contexto editorial, y que lo hacen desde algún punto de vista incisivo e innovador. Las obras citadas se eligieron porque en ellas se hace un uso de los elementos gráficos que las componen desde la superación y perversión de sus arbitrariedades.

\section{METODOLOGÍA Y OBJETIVOS}

El objetivo principal de esta investigación es la reflexión en torno a la obra "Anomalía..." y, por extensión, a todas aquellas que usen los elementos de edición impresa como parte integrante del objeto plástico o de su proceso. Es por este motivo que se hace necesario asentar esta serie en el caudal histórico y contemporáneo de aquellas obras que, moviéndose en la amplia horquilla entre la fotografía y el catálogo editorial, mantienen sus intereses pujando en el mismo sentido. Por otra parte, es también importante realizar el análisis formal y conceptual de esta obra desde la evolución que ha tenido lugar en su propio proceso de desarrollo, o sea desde la serie inmediatamente anterior a ella. Las conclusiones serán por tanto formales además de teóricas, teniendo en cuenta que lo deducido dará lugar a series subsiguientes.

\section{DESARROLLO DEL PROYECTO}

En el 1939 Richard Avedon y Truman Capote se dan la réplica el uno al otro en un diálogo imagen-texto dentro del libro "Observation". Pero es el director de arte Alexey Brodovitch el que finalmente estructura cada doble página con el fin de propiciar una determinada lectura visual. Alberto Bianda pone el énfasis de este trabajo en el siguiente dilema: la doble página está compuesta basándose en dos importantes elecciones estructurales: la primera es la dimensión y la segunda la posición (Bianda, 2009: 320). Este dilema no es tan simple como parece ya que de la relación entre ambas opciones se desprende el camino visual, la senda que traza el ojo lector -de la misma manera que lo hace el espectador de arte en formato bidimensional-. El texto, por el tratamiento caligramático que recibe especificamente en esta obra de Avedon y Capote, completa la forma de la realidad fotografiada, por la que podríamos decir que Alexey Brodovitch compone la página como si fuera un lienzo, atendiendo a formas y equilibrios, a derivas visuales, a planos que se suceden y a ritmos concatenados. El texto ocupa un lugar y tiene una forma, al igual que las fotografías con las que comparte la página. El peso visual de los elementos y personajes que se exhiben guían, alejan y acercan al lector/espectador en el desvelado paulatino de lo representado.

\footnotetext{
${ }^{1}$ A partir de ahora "Anomalía..."
} 

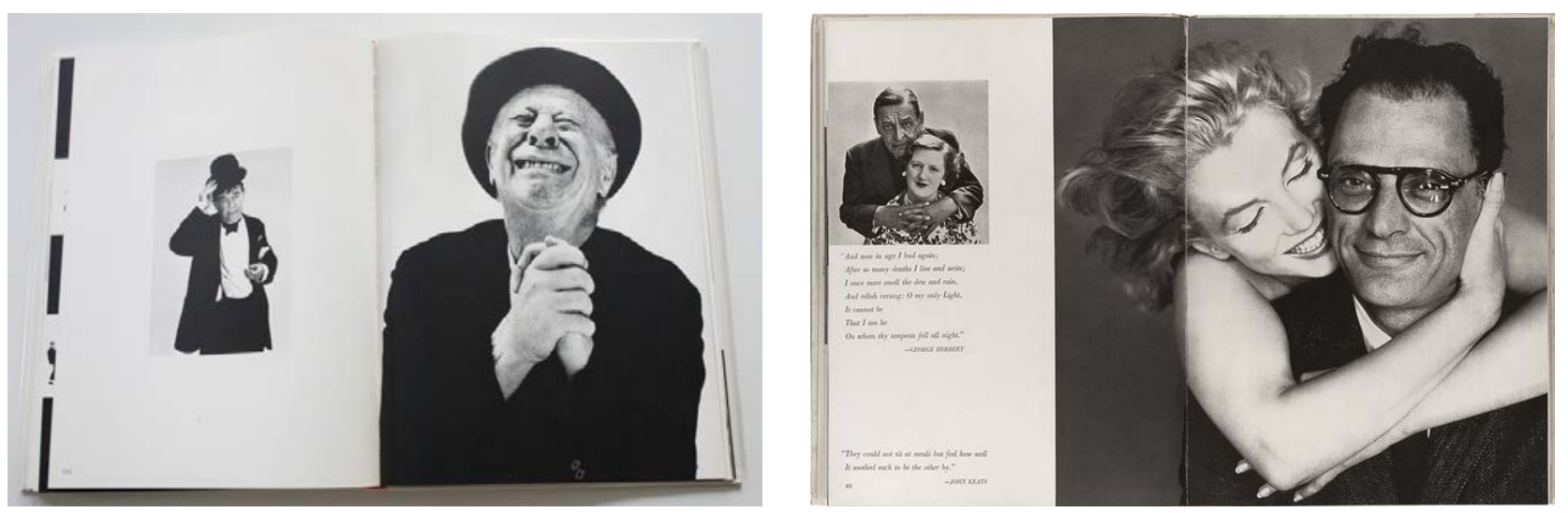

Figura 1. Avedon, R. y Capote, T. (1939) “Observation” (selección de páginas).

A partir de esta obra, los libros de fotografía proliferan por doquier a la misma vez que emerge un sector muy crítico que arremete contra ellos y la pobreza semántica a la que mantienen a la fotografía. Entre los autores pertenecientes a esta corriente destacamos al artista visual Allan Sekula el cual afirma que estos libros son una forma llena de clichés, que es el equivalente no comercial de anuncio fotográfico. Los ensayos fotográficos son el resultado de un tipo de estética de revista ilustrada de gran tirada, la estética de la mercalizable lectura rápida y vehemente en que el acto de leer queda supeditado al estímulo visual (Sekula, 2004: 45-46). Ejemplo de su posición marcadamente diferenciada de catálogo fotográfico al uso es el libro "Photography against the grain" (1973-78), a partir del cual David Campany hace la siguiente reflexión:

[...] creo que mi favorito de sus trabajos de foto-texto es "Meditaciones en un tríptico" (1973-78). Comprende tres instantáneas domésticas en color de un día en una historia familiar con un hombre en uniforme militar y un texto de alrededor de tres o cuatro mil palabras, en el que Sekula detalla la interpretación típica que casi cualquier persona haría de estas imágenes. Leer este texto es como experimentar una reproducción super lenta de esos primeros segundos en los que miras fotografías y llegas a conclusiones rápidas. Es un trabajo extraordinario que muestra la cantidad de información que procesamos, incluso en el compromiso más superficial con las fotos. Está incluido en "Photography against the grain" aunque También lo he visto en una configuración de galería, con las impresiones en la pared y el texto en un escritorio. Lo prefiero en el libro. (Campany, 2016)

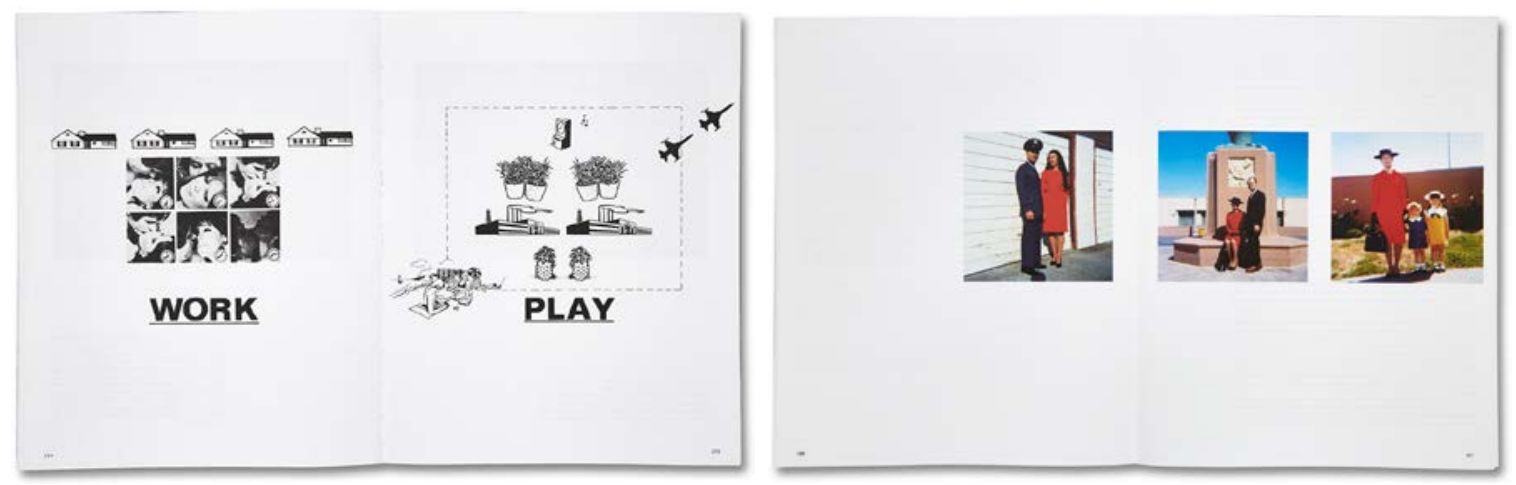

Figura 2. "School is a factory". En: Sekula, A. Photography against the grain (2016).

Figura 3. "Meditaciones en un tríptico". En: Sekula, A. Photography against the grain (2016).

Es interesante esta última apreciación que Campany hace de la obra de Sekula: Lo prefiero en el libro porque me ayuda a ahondar en el objetivo de la investigación. "Anomalía..." se beneficia de la problematización establecida entre la publicación y la imagen de sala, de la posibilidad de salvar el salto y la descontextualización de una obra que apunta a otro como formato original. No tanto a la manera en que Duane Michals solventa estas cuestiones sino de la forma en que lo hace Tracey Moffatt.

Para entender mejor esta diferenciación tengamos en cuenta lo que significa la fotografía para Michals: A mi juicio -dice Michals-, la fotografía a menudo es inadecuada y la completo con una escritura al lado de la foto, a veces una palabra es más importante que mil fotos (Soulage, 2005: 260). En la comparación que este autor hace entre el texto y la imagen ésta sale perdiendo por inadecuada e incompleta. Si yo les muestro la foto, es una experiencia en dos dimensiones; con el texto se convierte en algo en tres dimensiones [...] es como leer una historia de amor y enamorarse, realmente son dos experiencias diferentes (Soulage, 2005: 260). Hacia el lado opuesto se mueven las reflexiones de François Soulages el cual, cuando analiza las relaciones entre fotografia y lenguaje, destaca la superioridad de la fotografía: en fotografía el sentido estaría dado por la evidencia y la universalidad [...] el sentido saltaría a la vista; hasta un chino que no comprendiera el castellano reconocería un caballo al ver su foto en el Larousse; el descubrimiento del sentido 
gracias a la fotografía sería casi inmediato y la que se hace gracias a lenguaje sería fruto de mediaciones articuladas entre sí (Soulage, 2005: 256).

Como ya hemos dejado claro con antelación, el objetivo de este texto no es dilucidar cuál de los dos elementos (imagen y texto) queda por encima o por debajo del otro si coincidieran en una misma obra plástica, sino el de dejar patente que, por su pertenencia a distintos sistemas de comunicación más o menos inmediatos y arbitrarios, la relación innovadora que entre ellos se crea dentro del contexto editorial impulsa de una forma u otra el sentido plástico de la obra.

Es por esa pertenencia al entorno determinado que es el libro -o la "evocación" de ese "mundo externo" que el uso de ciertos elementos editoriales impulsa- la razón por la que la obra necesita una lectura nueva, pero es sobre todo la perversión del tratamiento de estos elementos editoriales lo que consigue, de manera directa, por un lado una revisión del acto de lectura y por otro una búsqueda de sentido que evita aquél que da la experiencia. Es lo que ocurre con la obra de Tracey Moffatt "Adventure Series" (2004). Cuando Moffatt introduce en cada formato tres fotografías en una disposición concreta, inevitablemente crea un paralelismo entre esta obra y la página de un cómic y ésto es lo que conlleva la frustración de expectativas en el espectador/lector ya que, casi de manera instantánea, constata que los códigos de lectura del cómic no son válidos para descifrar la lectura de esa página. Esta autora se aprovecha de las semejanzas formales de su obra con los elementos compositivos y estéticos del cómic - el viñeteado en mayor medida y la elipsis que éste conlleva pero también la utilización de ciertos símbolos iconográficos- para transgredir sus códigos narrativos espaciales y temporales (Caro Cabrera, 2015: 224).
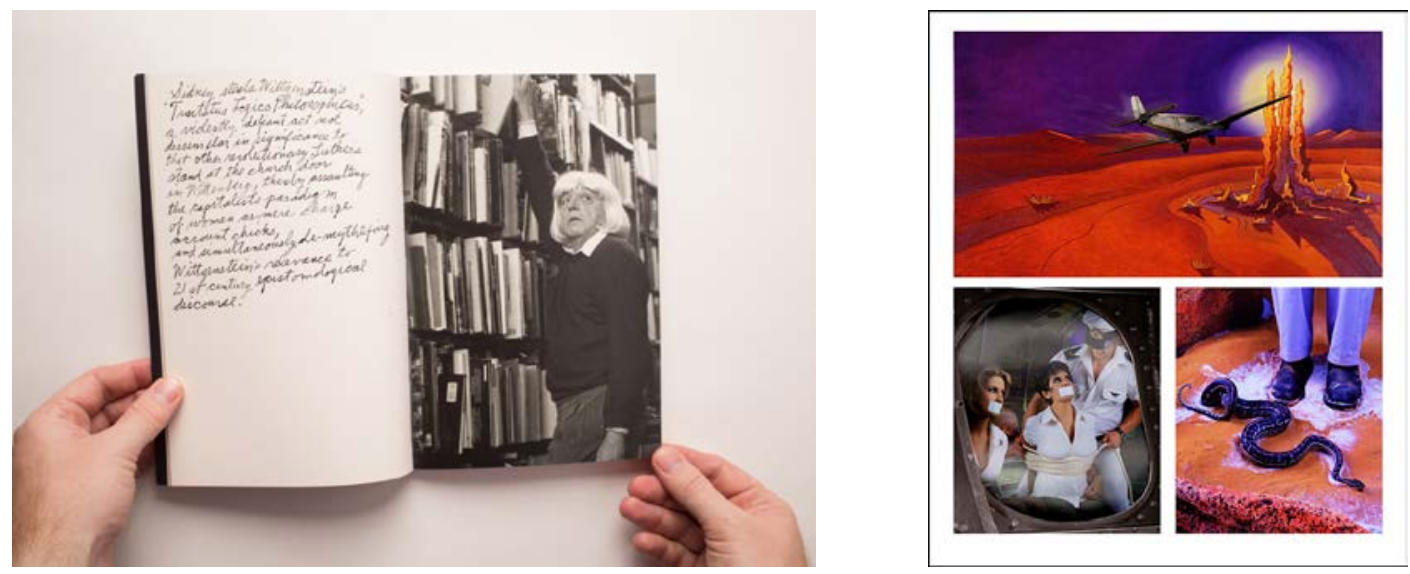

Figura 4. Duane Michals (2007). Foto follies: How Photography lost its virginity on the way to the bank. Figura 5. Tracey Moffatt. Adventure Series 1. 2004.

En el año 2016 las series fotográficas “La casita de mi padre” (2016, María Caro) y “Producción de un mundo” (2016, María Caro) son seleccionadas en el XVII concurso Encuentros de Arte Contemporáneo (EAC) y expuestas en el Museo de la Universidad de Alicante. Estas dos series están realizadas en torno a una línea de investigación clara: la fotografía como "figura" en el contexto de la página y devienen de una larga investigación en torno a la obra de la artista australiana Tracey Moffatt. La idea no es desarrollar un proyecto sobre la narración tanto como explorar los elementos y códigos narrativos para hacerlos inoperantes en el sentido referencial o descriptivo. En las series antes mencionadas la imagen comparte espacio con textos o con un sencillo número al pie de página. Elementos que posicionan cada una de estas fotografías en el seno de lo que pudiera ser un libro de instrucciones o un catálogo de casas con jardín. Varias ideas convergen en el proceso de producción: la noción de sitio como espacio que algo ocupa además del asedio al que somete lo que nos contextualiza; la idea Derridiana de parergon como el marco que se ubica al lado y además del argon, del hecho, de la obra, pero que no es ajeno, que afecta al interior de la operación y coopera con él desde cierto afuera (Derrida, 2010: XIII); y por último, el producto, el resultado de una relación innovadora que recae en aquel que completa el proceso de lectura desde su propia experiencia. 

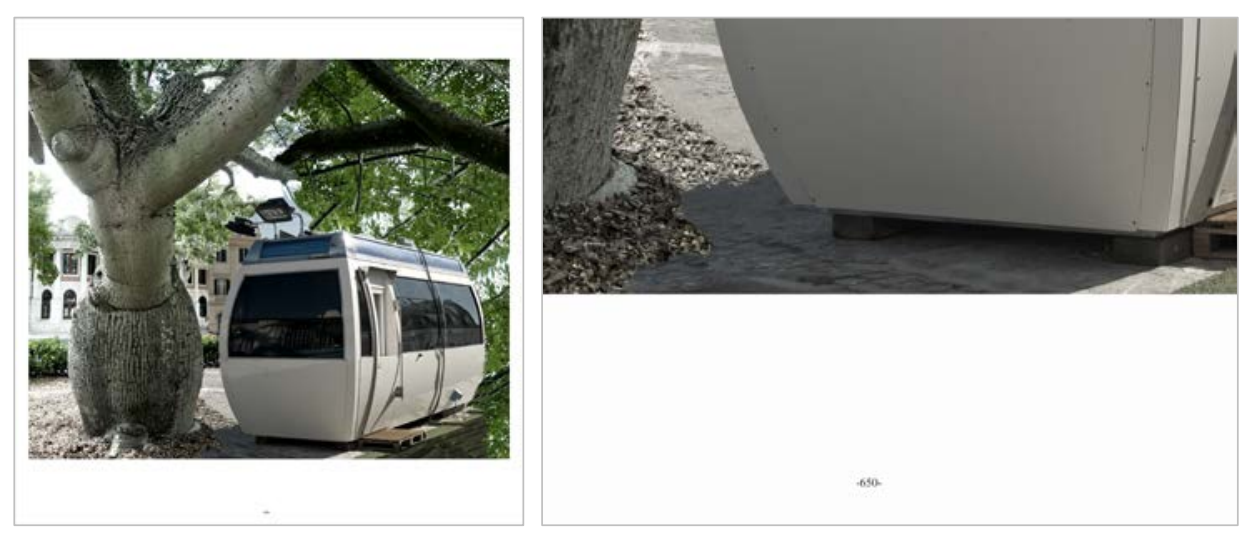

Figura 6. "La casita de mi padre: seiscientos cincuenta". María Caro, $2016.75 \times 75 \mathrm{~cm}$. (Obra completa y detalle)
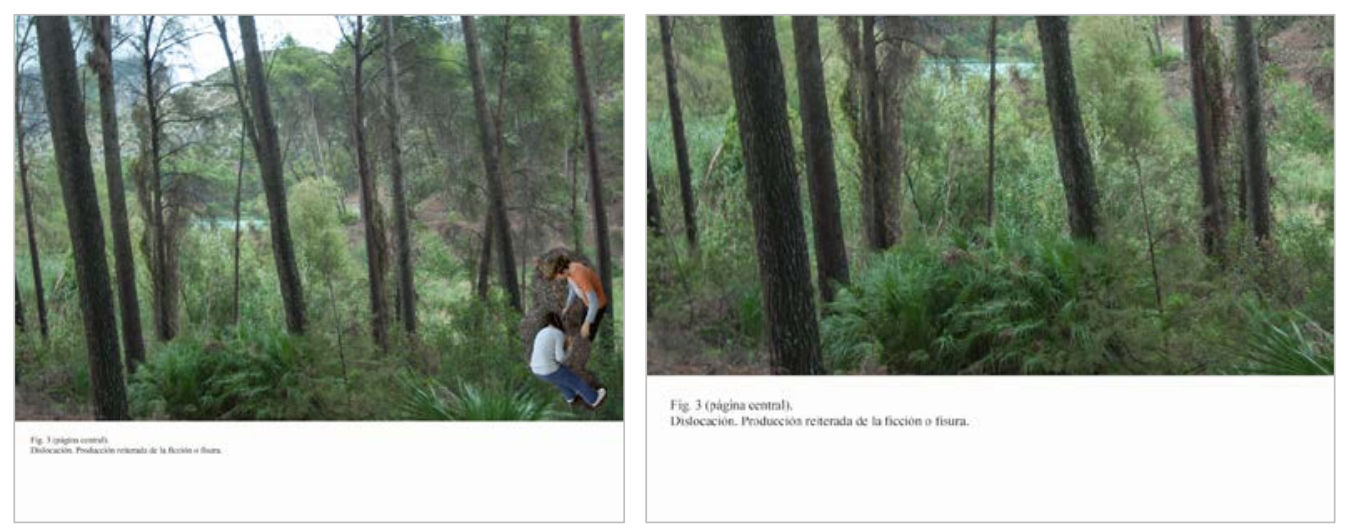

Figura 7. "Producción de un mundo. Fig.3 (página central)”. María Caro, 2016. (Obra completa y detalle)

Dice Susan Sontang que la fotografía en un libro es, obviamente, la imagen de una imagen (2010: 15). Ese mise en abyme es el que me interesa al abordar la idea de la imágen y la página que la alberga. Realmente es importante la figura a la que se nos remite a través del texto en un viaje no sólo conceptual sino también espacial; extensión de la mirada que va y vuelve en el impás que le proporciona la lectura, en lo que podría ser un contratiempo o permuta de la línea visual. Modificación de la mirada que trae consigo el cambio de ritmo narrativo, la pausa y reorganización mental de un discurso que se inicia de una manera y recalcula el rumbo cada vez que la narración remite al espectador hacia una figura con diferente cualidad visual.

Sin embargo, en ninguna de las obras que pertenecen a "La casita de mi padre" o a "Producción de un mundo" existe ese objeto exterior al que la obra remite. Ni hay libro o catálogo al que pertenezcan las imágenes, ni existe ese texto que aluda a la figura. La perversión no acaba ahí, el pie de la foto no resuelve la incognita visual, no cierra, no confiere sentido más allá del que el lector aporta. Dice también Sontang, parafraseando a Benjamin, que un subtítulo correcto bajo una imagen podría rescatarla de las rapiñas del amaneramiento y conferirle un valor de uso revolucionario (Sontang, 2008: 110) A partir de esta reflexión el pie se convierte en un pozo $\sin$ fondo en el mundo de las posibilidades significativas. Los pies tienden a invalidar lo que es evidente a los propios ojos, pero ningún pie puede restringir o asegurar permanentemente el significado de una imagen (Sontang, 2008: 111). La palabra clave es "permanentemente".

"Anomalía..." es una serie fotográfica compuesta por cuatro impresiones fotográficas de gran formato sobre papel. La forma final de cada obra está sujeta a la combinatoria de la posición y la dimensión de sus elementos para terminar descansando en estructuras compositivas básicas muy cercanas a las que rigen la bidimensionalidad pictórica. La extrañeza a la que da lugar esta combinatoria y las evocaciones a las que nos remite es lo que otorga a esta obra su sentido último.

Cada uno de los elementos de esta serie asumen su significado desde su relación con el otro (imagen con imagen, imagen con pie de foto, imagen con figura, figura con texto; imagen con pie de foto y con página...), y presentan su producto como algo flotante, ambigüo e incapáz de tomar asiento. Interesa en este sentido el tratamiento de los textos que aparecen en las pinturas de Muntean y Rosenblund. Según estos autores el texto forma una capa aparte, [...] de esta forma potenciamos la idea de que las propias imágenes son constructos. [...] En un principio, piensas que son frases llenas de sentido, cosas importantes sobre la vida y cómo vivirla. Pero de pronto te entra la sensación de que no sabes quién está hablando, ni si tiene sentido alguno lo que está diciendo. Es justo ese momento en el que el sentido empieza a tambalearse (Muntean y Rosenblund, 2018). 
La imagen producida, junto con la ambiguedad en el sentido de los textos al pie, potencian la atmósfera extraña de "Anomália..." Ninguno de los elementos de la serie, ni siquiera gracias a las evocaciones editoriales que sucita, conlleva una narración, descripción o instrucción. La temporalidad se queda paralizada en la forma.
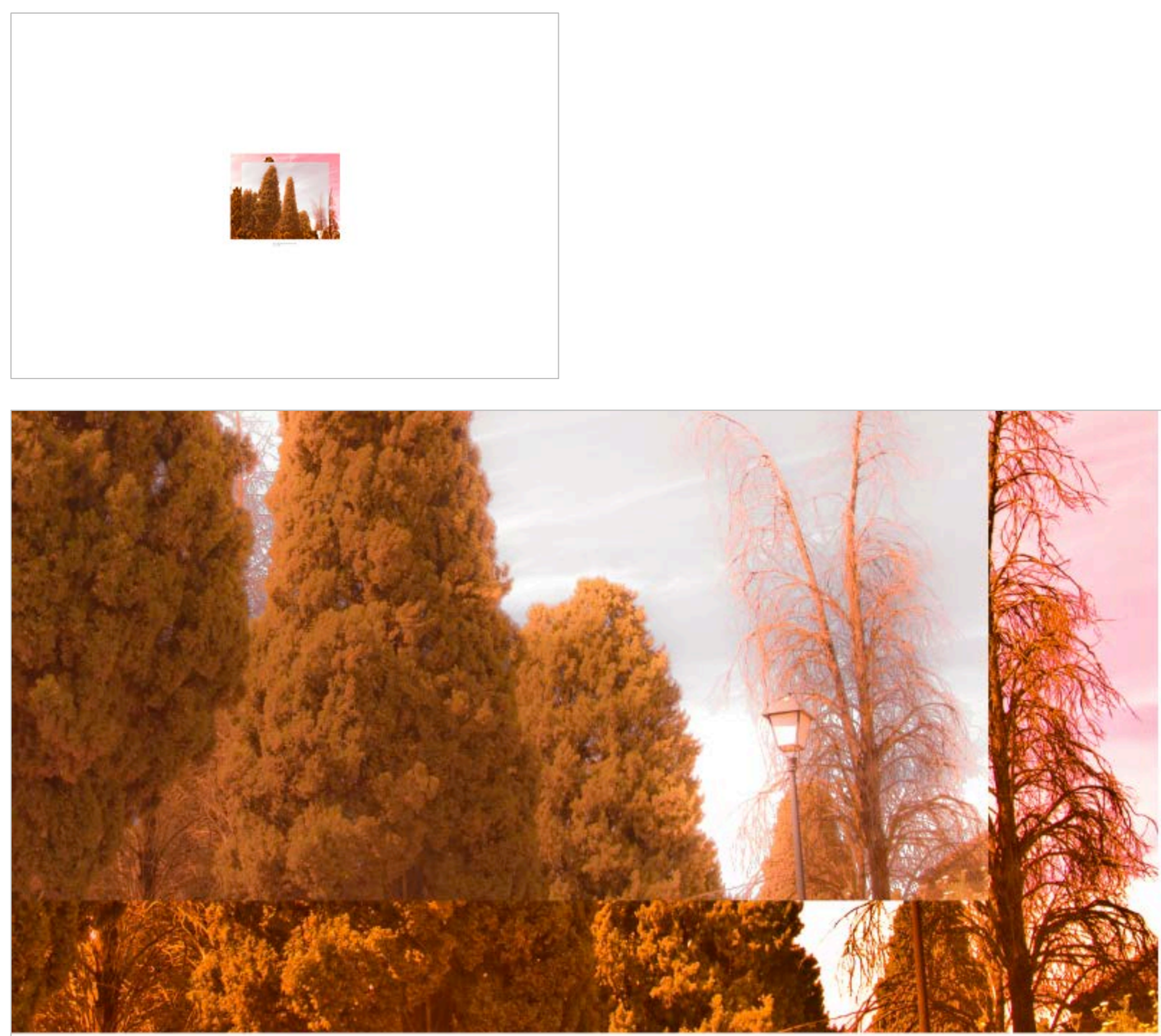

Fig. 12. Caudal de agua insuliciente (verificar y corregir).

Figura 8. “Anomalía en el libro de Kells I”. María Caro, 2019. (Obra completa y detalle) 
Anomalía en el libro de Kells. Dinámicas del acontecimiento plástico

IV Congreso INTERNACIONAL DE INVESTIGACIÓN EN ARTES VISUALES ANIAV 2019 IMAGEN [N] VISIBLE]

http://dx.doi.org/10.4995/ANIAV.2019.8985
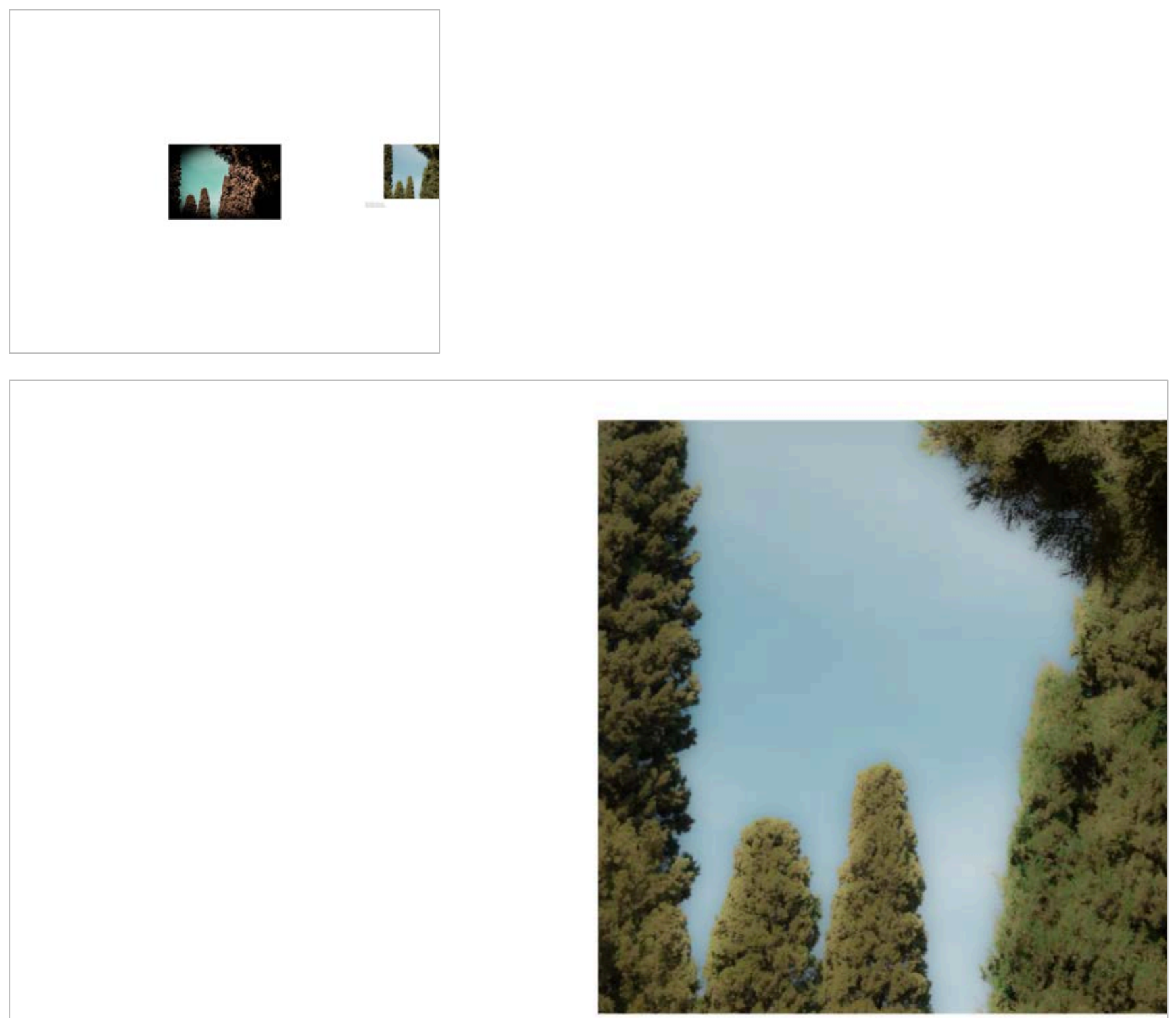

Fì.1. Coutrol del sisema de parsi-

micato no lineal y cotcicucia de se

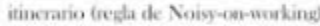

Figura 9. "Anomalía en el libro de Kells II". María Caro, 2019. (Obra completa y detalle) 


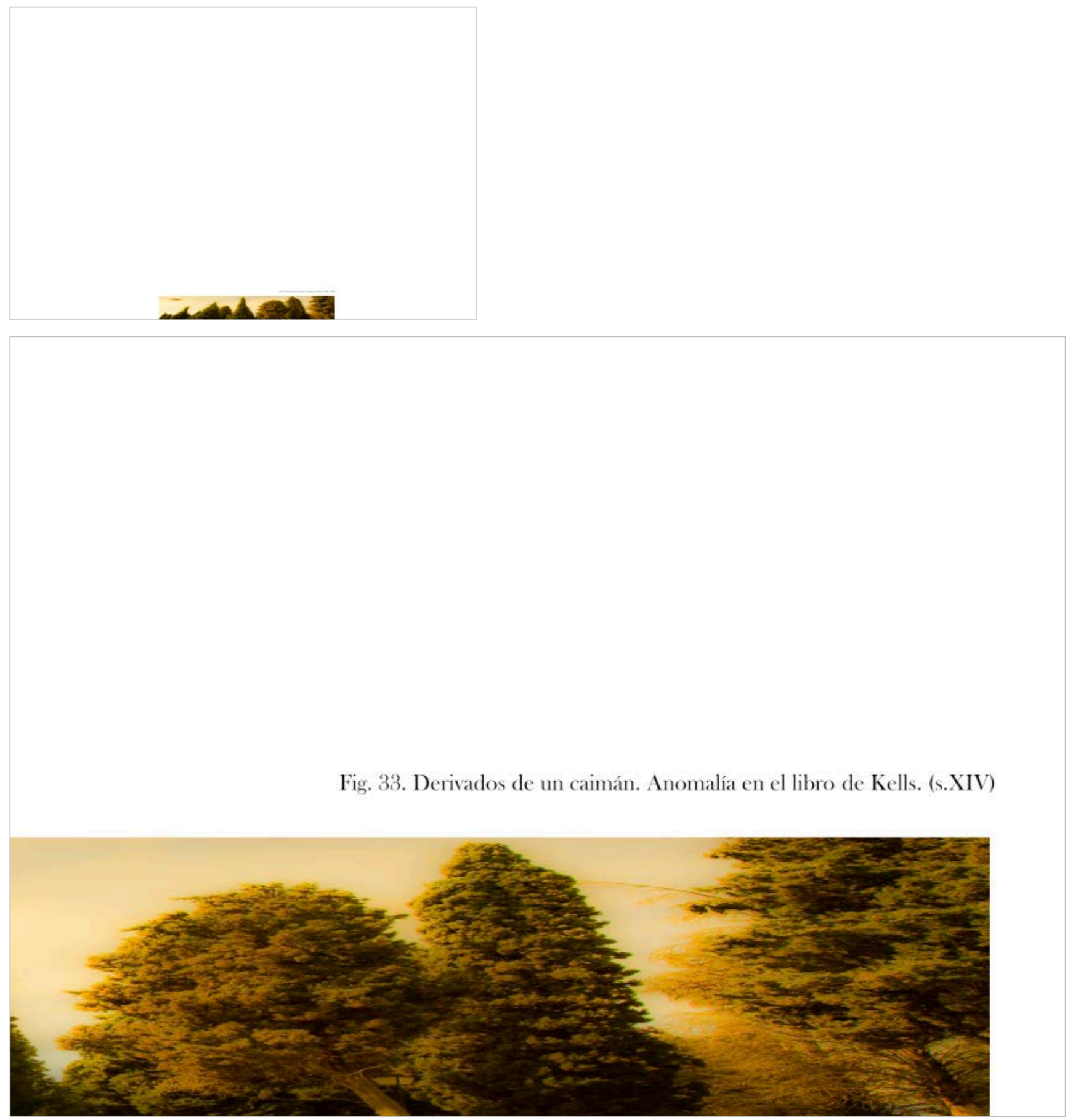

Figura 10. "Anomalía en el libro de Kells III". María Caro, 2019. (Obra completa y detalle) 


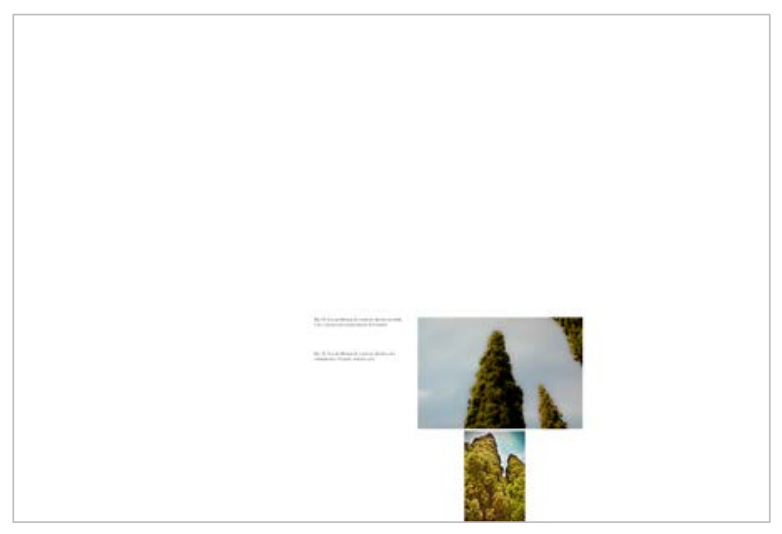

Fig. 39. Los problemas de contexto afectan sin duda a los concurrentes (la lengua pegada al cielo).

Fig. 40. Los problemas de contexto afectan a los subsiguientes. La uña saca la mano.

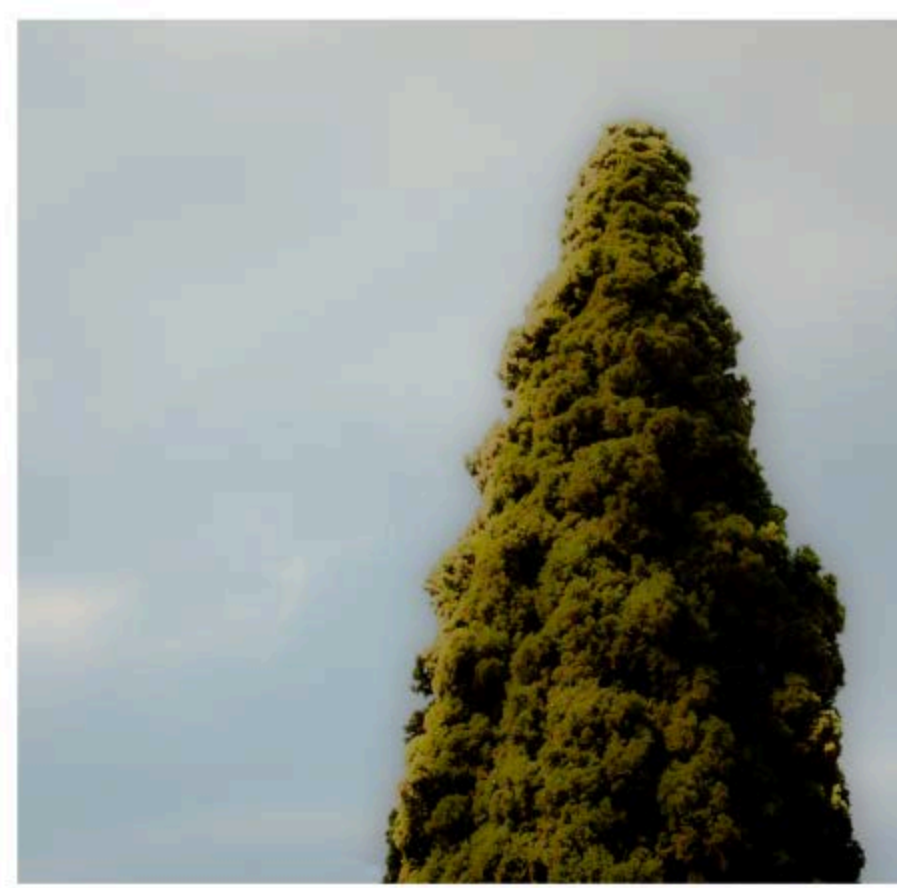

Figura 11. "Anomalía en el libro de Kells IV". María Caro, 2019. (Obra completa y detalle)

\section{CONCLUSIONES}

Las conclusiones de esta investigación van encaminadas a dejar constancia de las distintas posibilidades plásticas que se abren atendiendo a la lo deducido ante las obras analizadas. Como hemos visto en la obra de Moffatt "Adventure Series" (2004), la evocación de una página, afianza en todos los elementos y simbolos gráficos que contextualiza el sentido de pertenencia a un mismo relato, posiciona la obra en una línea temporal heredada de la gramática y la oralidad, y concede la illusión de formar parte de un todo que la sobrepasa y al cual se refiere. Por lo tanto la posibilidad del acto de leer no confiere solamente una determinada conducta al espectador/lector que se posiciona frente a la obra, sino que emplaza la obra en un lugar entre lo pasado (la página anterior) y lo futuro (la página siguiente), otorgándole esa dimensión que es el tiempo y que la hermana de manera clásica con lo narrativo. Esta 
suposición de que la temporalidad estructura la obra se ve indudablemente subvertida en "Anomalía..." la cual necesita de esa primera frustración del lector/espectador para alcanzar su sentido estético.

Como ocurre en la obra de Michals, un texto al lado de una imagen puede completarla a nivel del significado; también puede terminarla a nivel formal, como ocurre en el diseño editorial de Alexey Brodovitch en "Observations"; o incluso -tal y como Campany comenta del texto de Sekula en "Meditaciones en un tríptico"- leer ese texto puede llevarnos a experimentar una mirada. En la serie fotográfica "Anomalía...", las relaciones entre uno y otro sistema están en disposición de capas pictóricas en función de aquello que los sobrepasa y los engloba: la obra plástica -que no el libro-, de sus necesidades y sus objetivos plásticos -que no literarios.

Por ultimo decir que en "Anomalía en el libro de Kells" las imágenes fotográficas no pueden ser consideradas, tal y como lo son las palabras, como niveles básicos de significación con funciones invariables e inequívocas en una posible combinatoria. La fotografía como significante no está ligada irremediablemente a un significado, por lo tanto su sentido se considera exclusivamente una fijación momentánea, con todas las posibilidades que este aspecto despliega en la obra final.

\section{FUENTES REFERENCIALES}

Bianda, A. (2009). Ver textos, leer imágenes. El libro de la fotografía. En: Scianna F. y Ansón A. (eds.), Las palabras y las fotos. Literatura y fotografía. Madrid: Ministerio de Cultura.

Capote, T. y Avedon, R. (1959). Observations. New York: Simon \& Schuster.

Caro Cabrera, M. (2015). El relato como irresolución narrativa. El caso de Adventure Series de Tracey Moffatt. [Tesis Doctoral]. Málaga: Publicaciones y Divulgación científica, Universidad de Málaga. Disponible en: https://riuma.uma.es/xmlui/handle/10630/10150

Gómez Isla, J. (2005). Fotografía de creación. San Sebastián: Editorial Nerea.

Michals, D. (2007). Foto Follies: How Photography lost its Virginity on the Way to the Bank. Thams and Hudson, Reino Unido.

Muntean y Rosenblund. (2018.) Metrópolis. Radio Televisión Española. Disponible en:

http://www.rtve.es/alacarta/videos/metropolis/metropolis-muntean-rosenblum/4647674/

Plissart, M.F. y Derrida, J. (1985). Droit de regards. Bruselas: Impressions nouvelles.

Sekula, A. (2004). Desmantelar la modernidad, reinventar el documental. Notas sobre la política de la representación. En: Jorge Ribalta (ed.), Efecto Real. Debates posmodernos sobre la fotografía. Barcelona: Editorial Gustavo Gili.

Sekula, A. (2016). Photography against the grain. London: Mack.

Sontang, S. (2008). Sobre la fotografía. Barcelona: Randon House Mondadori.

Soulage, F. (2005). Estética de la fotografía. Buenos Aires: La marca ediciones.

Shah, S. (2016). Allan Sekula, Against the grain: An interview with David Campany. American suburb X. Disponible en: https://www.americansuburbx.com/2016/11/allan-sekula-against-the-grain-an-interview-with-david-campany.html

https://www.roslynoxley9.com.au/artists/26/Tracey Moffatt/306/32771/

https://mackbooks.co.uk/products/photography-against-the-grain-essays-and-photo-works-1973-1983-br-allan-sekula 